\title{
ISU METAFISIKA DALAM SAINS: (Kemampuan Air dalam Mentransmisi Emosi Manusia)
}

\author{
Armansyah Putra $^{{ }^{\star}}$ dan Tomi Hidayat ${ }^{2}$ \\ ${ }^{1}$ Program Studi Pendidikan Biologi, FKIP, Universitas Samawa Sumbawa Besar \\ ${ }^{2}$ Program Studi Pendidikan Biologi FKIP, Universitas Muhammadiyah Bengkulu \\ *E_mail : arman091088@gmail.com
}

\begin{abstract}
Abstrak
Kajian Metafisika menjelaskan studi keberadaan atau realitas. Manusia secara tidak sadar selalu memiliki rasa ingin tahu tentang asal atau hakikat objek (fisik) di dunia. Setiap pengetahuan yang diketahui oleh manusia membutuhkan penafsiran-penafsiran secara ilmu pengetahuan. Membicarakan realitas sebuah objek, merupakan kegiatan yang tidak ada ujung pangkalnya karena masalah yang dikaji tidak dapat dipecahkan oleh paradigma keilmuan. IImu pengetahuan berupaya memecahkan masalah-masalah yang ada dengan konsepsi teoritis, asumsi, postulat, tesis. paradigma baru, dan pemecahan masalah yang baru, serta imajinasi akan dapat membuka kemungkinan-kemungkinan atau peluang-peluang untuk mendapatkan jawabannya. Keberadaan metafisika dalam ilmu pengetahuan memberikan banyak wawasan bagaimana metafisika merupakan hal substantive dalam menelaah lebih jauh konsep keilmuan dalam menunjang kejayaan manusia dalam berpikir dan menganalisis. Contoh dari metafisika adalah air yang mampu mentransmisikan emosi yang dimiliki oleh manusia. Air, layaknya manusia, juga bisa mendengar, melihat, merasakan, dan merespons setiap informasi yang kita berikan kepadanya. Masaru Emoto telah membuktikan bahwa air yang diberi respons positif, termasuk doa, akan menghasilkan bentuk kristal yang indah.
\end{abstract}

Kata kunci: Metafisika, air, transmisi, manusia.

\section{PENDAHULUAN}

Metafisika merupakan bagian dari aspek ontologi dalam kajian filsafat. Konsepsi metafisika berasal dari bahasa Inggeris: metaphysics, Latin: metaphysica. Metafisika merupakan bagian Falsafah tentang hakikat yang ada di sebalik fisika. Hakikat yang bersifat abstrak dan di luar jangkauan pengalaman manusia. Tegasnya tentang realitas kehidupan di alam ini: dengan mempertanyakan yang Ada (being), Alam ini wujud atau tidak? Siapakah kita? Apakah peranan kita dalam kehidupan ini?. Metafisika secara prinsip mengandung konsep kajian tentang sesuatu yang bersifat rohani dan yang tidak dapat diterangkan dengan kaedah penjelasan yang ditemukan dalam ilmu yang lain. Pandangan beberapa kalangan antara metafisika dan sains sangat berbeda-beda. Beberapa kalangan peneliti atau saintis memandang bahwa sains itu nyata dan sangat tidak berhubungan dengan hal-hal metafisika, seperti tidak berdasarkan logika, tidak rasional, atau tidak nyata. Akan tetapi, beberapa kalangan setuju bahwa metafisika memiliki hubungan yang erat dengan sains dalam beberapa segi. Oleh karena itu, banyak perdebatan dalam pandangan metafisika yang memiliki hubungan dengan sains.

Dalam sejarah, metafisika dan sains pernah memiliki hubungan yang erat dimana keduanya dinilai sebagai suatu kesatuan dan berada dalam wilayah yang sama yakni, filsafat alam (natural philosophy). apakah lantas metafisika dan sains adalah dua hal yang benar-benar berbeda dan tak bisa didamaikan? Apakah mungkin metafisika memiliki nilai positif dalam sains? Pertanyaan-pertanyaan semacam ini melahirkan perdebatan panjang. Ketidakpercayaan terhadap metafisika di dalam sains tidak hanya diakui oleh pihak ilmuwan sebagai pelaku sains, melainkan juga dari para pemikir filsafat. Immanuel Kant yang menyatakan bahwa metafisika merupakan ketidakwajaran dalam pemahaman (understanding). Bahkan menurut Carnap (1963) dalam Callender (2011: 34), bagi para pemikir yang terinspirasi oleh Kant, metafisika dianggap telah kehilangan kontak dengan yang empiris.

Pandangan ini memuat konsekuensi logis dimana sains yang lekat dengan berbagai data empiris sungguh bertolak belakang bahkan tidak memiliki hubungan apa-apa dengan metafisika. Dengan 
demikian harus ada batas tegas antara sains dengan metafisika.

\section{HASIL DAN PEMBAHASAN}

\section{Pengertian Metafisika}

Metafisika merupakan cabang filsafat yang mempelajari penjelasan asal atau hakekat objek (fisik) di dunia. Dimana metafisika mempersoalkan realitas dan dunia dengan segala struktur dan dimensinya. Apa yang sungguh-sungguh 'ada' yang paling utama? Apakah itu 'kehidupan'? apakah itu 'dunia fisik'? Apakah keseluruhan kenyataan itu tunggal atau majemuk? Apakah kenyataan itu satu ragam ataukah bermacam ragam? Secara garis besar, pandangan filsafat terkait dengan pokok soal tersebut dapat dikelompokan antara monisme dan pluraisme, yang baik monisme maupun pluralisme dapat bersifat spiritualistis ataupun materialistis, (Baker, 1992).

Menurut para pemikir metafisis seperti Plato dan Aristoteles memberikan asumsi dasar bahwa dunia atau realitas adalah yang dapat dipahami (intelligible) yang mana setiap aliran metafisika mengklaim bahwa akal budi memiliki kapasitas memadai untuk memahami dunia. Seolah-olah akal budi memiliki kualitas "ampuh" untuk menyibak semua realitas mendasar dari segala yang ada. Sedangkan menurut Hamlyn (1993) metafisika adalah bagian kajian filsafat yang paling abstrak dan dalam pandangan sementara orang merupakan bagian yang paling "tinggi" karena berurusan dengan realitas yang paling utama, berurusan dengan "apa yang sungguh-sungguh ada" yang membedakan sekaligus menentukan bahwa sesuatu itu mungkin ataukah tidak. Sekalipun demikian, subjek yang pasti dari kajian metafisika secara terus menerus dipertanyakan, demikian juga validitas klaim-klaimnya dan kegunaannya. Berikut adalah pendapat para ilmuwan tentang Metafisika. Alfred, J. Ayer menyatakan bahwa sebagian besar perbincangan yang dilakukan oleh para filosof sejak dahulu sesungguhnya tidak dapat dipertanggungjawabkan dan juga tidak ada gunanya, problem yang diajukan dalam bidang metafisika adalah problem semu, artinya permasalahan yang tidak memungkinkan untuk dijawab, berkaitan dengan pendapat Ayer tersebut. Dan Katsoff menyatakan bahwa sepertinya Ayer berupaya untuk menunjukan bahwa naturalism, materialism, dan lainnya merupakan pandangan yang sesat. Adapun Penentang lain adalah Luwig Winttgenstien yang menyatakan bahwa metafisika bersifat the mystically, hal-hal yang tak dapat diungkapkan ke dalam bahasa yang bersifat logis. Sedangkan menurut (Firman, 2006) Metafisika adalah kajian filsafat yang mendasar dan komprehensif mengenai seluruh realita atau tentang keberadaan. Dengan demikian, metafisika adalah bagian kajian filsafat tentang sifat dan fungsi teori tentang realita.

Manfaat metafisika bagi pengembangan ilmu dikatakan oleh Thomas S. Kuhn (1989) yakni ketika kumpulan kepercayaan belum lengkap faktanya, maka ia mesti dipasok dari luar, antara lain adalah ilmu pengetahuan lain, peristiwa sejarah, pengalaman personal, dan metafisika, misalnya adalah upaya-upaya untuk memecahkan masalah yang tak dapat dipecahkan oleh paradigm keilmuan yang lama dan selama ini dianggap mampu memecahkan masalah dan membutuhkan paradigm baru, pemecahan masalah baru, hal ini hanya dapat dipenuhi dari hasil perenungan metafisik yang dalam banyak hal memang bersifat spekulatif dan intuitif, hingga dengan kedalaman kontemplasi serta imajinasi akan dapat membuka kemungkinan-kemungkinan atau peluang-peluang konsepsi teoritis, asumsi, postulat, tesis dan paradigm baru untuk memecahkan masalah yang ada. Sumbangan metafisika terhadap ilmu pengetahuan tidak dapat disangkal lagi adalah pada fundamental ontologisnya. Sumbangan metafisika pada ilmu pengetahuan adalah persinggunggan antara metafisika dan ontology dengan epistimologi. Dalam metafisika yang mempertanyakan apakah hakikat terdalam dari kenyataan yang diantaranya dijawab bahwa hakikat terdalam dari kenyataan adalah materi, maka munculah paham materialism, sedangkan dalam epistimologi yang dimulai dari pertanyaan bagaimanakah cara kita memperoleh pengetahuan? Descartes telah menjelaskan bahwa kita memperoleh pengetahuan melalui akal dan dari pemikiran tersebut maka munculah rasionalisme. Sedangkan John Locke telah menjawab pertanyaan tersebut bahwa pengetahuan diperoleh dari pengalaman, maka ia telah melahirkan aliran empirisme. Metafisika menuntut orisinalitas berpikir yang biasanya muncul melalui kontemplasi atau intuisi berupa kilatan-kilatan mendadak akan sesuatu, 
hingga menjadikan para metafisikus menyodorkan cara berpikir yang cenderung subjektif dan menciptakan terminology filsafat yang khas. Situasi semacam ini dinyatakan oleh Van Peursen sangat diperlukan untuk pengembangan ilmu dalam rangka menerapkan heuristika. Berkaitan dengan pembentukan minat intelektual, maka metafisika mengajarkan mengenai cara berpikir yang serius dan mendalam tentang hakikat-hakikat segala sesuatu yang bersifat enigmatik, hingga pada akhirnya melahirkan sikap ingin tahu yang tinggi sebagaimana mestinya dimiliki oleh para intelektual. Metafisika mengajarkan pada peminat filsafat untuk mencari prinsip pertama sebagai kebenaran yang paling akhir.

\section{Manfaat Metafisika bagi Pengembangan Ilmu (aksiology)}

Axiologi sebagai filsafat yang membahas apa kegunaan ilmu pengetahuan bagi manusia. Aksiologi menjawab, untuk apa pengetahuan yang berupa ilmu itu di pergunakan? Bagaimana kaitan antara cara penggunaan tersebut dengan kaidah-kaidah moral? Bagaimana penentuan objek yang ditelaah berdasarkan pilihan-pilihan moral? Bagaimana kaitan antara teknik prosedural yang merupakan operasionalisasi metode ilmiah dengan norma-norma moral? Dengan demikian Aksiologi adalah nilai-nilai (value) sebagai tolok ukur kebenaran (ilmiah), etik, dan moral sebagai dasar normative dalam penelitian dan penggalian, serta penerapan ilmu. Pembahasan yang mendalam tentang keberadaan metafisika dalam ilmu pengetahuan memberikan banyak wawasan bagaimana metafisika merupakan hal substantive dalam menelaah lebih jauh konsep keilmuan dalam menunjang kejayaan manusia dalam berpikir dan menganalisis. Sehingga manfaat yang mutlak terhadap pengembangan ilmu dipaparkan Kuhn bahwa kontribusi metafisika terletak pada awal terbentuknya paradigma ilmiah, ketika kumpulan kepercayaan belum lengkap pengumpulan faktanya, maka ia harus dipasok dari luar, antara lain: metafisika, sains yang lain, kejadian personal dan historis serta metafisika mengajarkan sikap open-ended, sehingga hasil sebuah ilmu selalu terbuka untuk temuan dan kreativitas baru. (Wiramihardja, 2006)

Selanjutnya Kennick juga mengungkapkan bahwa metafisika mengajarkan cara berfikir yang serius, terutama dalam menjawab problem yang bersifat enigmatif (teka-teki), sehingga melahirkan sikap dan rasa ingin tahu yang mendalam. Perdebatan dalam metafisika melahirkan berbagai aliran, mainstream seperti : Monisme, Dualisme, Pluralisme, sehingga memicu proses ramifikasi, berupa lahirnya percabangan ilmu. Sementara Van Peursen mengatakan bahwa metafisika menuntut orisinalitas berfikir, karena setiap metafisikus menyodorkan cara berfikir yang cenderung subjektif dan menciptakan terminology filsafat yang khas. Situasi semacam ini diperlukan untuk pengembangan ilmu dalam rangka menerapkan heuristika. Metafisika mengajarkan pada peminat filsafat untuk mencari prinsip pertama (First Principle) sebagai kebenaran yang paling akhir. Disamping itu Bakker mengemukakan bahwasanya metafisika mengandung potensi untuk menjalin komunikasi antara pengada yang satu dengan pengada yang lain. Aplikasi dalam ilmu berupa komunikasi antar ilmuwan mutlak dibutuhkan, tidak hanya antar ilmuwan sejenis, tetepi juga antar disiplin ilmu, sehingga memperkaya pemahaman atas realitas keilmuwan.

\section{Kemampuan Air Mentransmisi Emosi Manusia}

Para ahli mengungkapkan bahwa manusia tak akan bertahan hidupnya bila tidak mampu memelihara harmoni dan jaring kehidupan, termasuk dengan lingkungan alamnya. Manusia pasti akan kalah jika memusuhi alam. Itulah sebabnya, bumi ini disebut "ibu" (mother earth), karena bumilah yang senantiasa mengasuh dan menopang seluruh kebutuhan manusia. Berbagai penelitian ilmiah mutakhir menunjukkan temuan-temuan baru bahwa semua benda yang selama ini kita anggap "bisu dan mati" ternyata memiliki "jiwa" dan bereaksi terhadap sikap manusia.

Melalui buku The Message from Water, Masaru Emoto, peneliti dari Jepang, berhasil mengungkapkan misteri air lebih mendalam. Dalam buku ini Masaru membuktikan bahwa air adalah bagian dari makhluk hidup. Menurut dia, air itu hidup. Air, layaknya manusia, juga bisa mendengar, melihat, merasakan, dan merespons setiap informasi yang kita berikan kepadanya. Masaru Emoto telah membuktikan bahwa air yang diberi respons positif, termasuk doa, akan menghasilkan bentuk kristal yang indah. Jika respons yang diberikan negatif, air tidak akan dapat membentuk kristal. Dan ini 
sesuai dengan firman Allah didalam Al-Qur'an Surat Anbiya ayat 30 yang artinya : "Dan Kami ciptakan dari air segala sesuatu yang hidup." (QS. Al Anbiya : 30). Dalam kitab-kitab tafsir klasik, ayat tadi diartikan bahwa tanpa air semua akan mati kehausan. Air murni dari mata air di Pulau Honshu dido'akan secara agama Shinto, lalu didinginkan sampai -5 derajat $C$ di laboratorium, lantas difoto dengan mikroskop elektron dengan kamera kecepatan tinggi. Ternyata molekul air membentuk kristal segi enam yang indah.

Percobaan diulangi dengan membacakan kata, "Arigato (terima kasih dalam bahasa Jepang)" di depan botol air tadi. Kristal kembali membentuk sangat indah. Lalu dicoba dengan menghadapkan tulisan huruf Jepang, "Arigato". Kristal membentuk dengan keindahan yang sama (Gambar 1.a). Selanjutnya ditunjukkan kata "setan", kristal berbentuk buruk (Gambar 1.b). Diputarkan musik Symphony Mozart, kristal muncul berbentuk bunga (Gambar 1.c). Ketika musik heavy metal diperdengarkan, kristal hancur (Gambar 1.d). Dan ketika dicoba dibacakan do'a Islam, kristal bersegi enam dengan lima cabang daun muncul berkilauan seperti yang terlihat pada gambar 1.e.

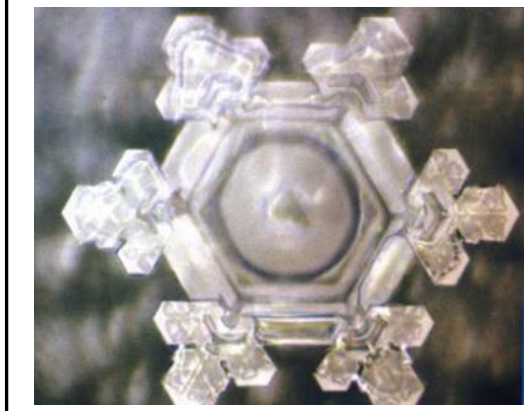

(a)

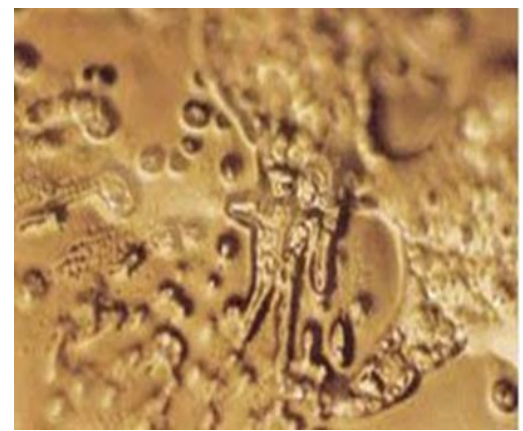

(d)

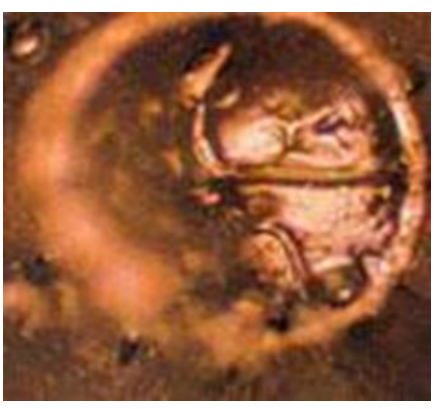

(b)

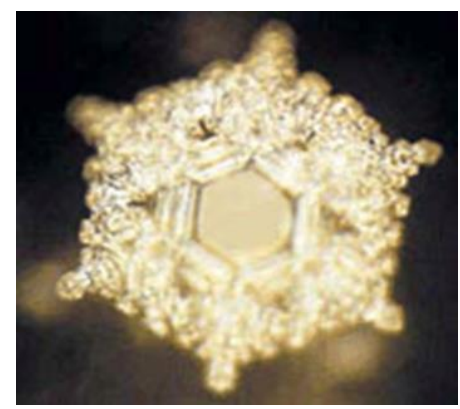

(c)

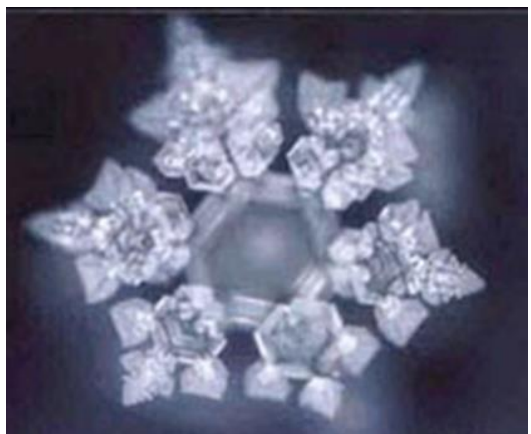

(e)

Gambar 1. Pola air setelah diberikan beberapa perlakuan dan difoto dengan mikroskop elektron dengan kamera kecepatan tinggi

Dr. Emoto akhirnya berkeliling dunia melakukan percobaan dengan air di Swiss, Berlin, Prancis, Palestina, Saudi Arabiah dan ia kemudian diundang ke Markas Besar PBB di New York untuk mempresentasikan temuannya pada bulan Maret 2005 lalu. Inilah sampel air yang diambil di mekkah tepatnya di masjidil haram yaitu air zam-zam, dan ternyata kristal terindah didunia adalah kristal air zam-zam. Mengapa ? karena setiap tahun jutaan manusia yang berkumpul melaksanakan ibadah haji selalu memberikan doa-doa dan kata-kata positif tiada henti dari waktu ke waktu. Pola gambar air zamzam seperti pada gambar 2 . 


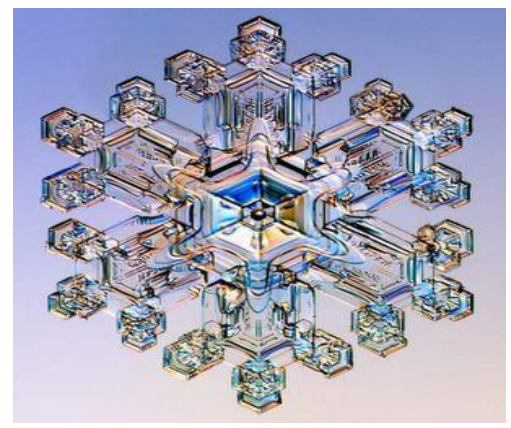

Gambar 2. Pola air zam-zam

Ternyata air bisa "mendengar" kata-kata, bisa "membaca" tulisan, dan bisa "mengerti" pesan. Dalam bukunya The Hidden Message in Water, Dr. Masaru Emoto menguraikan bahwa air bersifat bisa merekam pesan, seperti pita magnetik atau compact disk. Semakin kuat konsentrasi pemberi pesan, semakin dalam pesan tercetak di air. Air bisa mentransfer pesan tadi melalui molekul air yang lain. Barangkali temuan ini bisa menjelaskan, kenapa air putih yang dido'akan bisa menyembuhkan si sakit. Dulu, hal tersebut kita anggap musyrik, atau paling sedikit kita anggap sekadar sugesti, tetapi ternyata molekul air itu menangkap pesan do'a kesembuhan, menyimpannya, lalu vibrasinya merambat kepada molekul air lain yang ada di tubuh si sakit.

Tubuh manusia memang $75 \%$ terdiri atas air. Otak $74,5 \%$ air. Darah $82 \%$ air. Tulang yang keras pun mengandung $22 \%$ air. Air putih galon di rumah, bisa setiap hari dido'akan dengan khusyu kepada Allah, agar anak yang meminumnya shaleh, sehat, dan cerdas, dan agar suami yang meminum tetap setia. Air tadi akan berproses di tubuh meneruskan pesan kepada air di otak dan pembuluh darah. Dengan izin Allah, pesan tadi akan dilaksanakan tubuh tanpa kita sadari. Bila air minum di suatu kota dido'akan dengan serius untuk keshalehan, insya Allah semua penduduk yang meminumnya akan menjadi baik.

\section{PENUTUP}

Berdasarkan penelitian Dr. Masaru, semakin jelas terlihat bahwa kualitas air dapat menjadi lebih baik atau lebih buruk, bergantung pada informasi yang diterimanya. Hal ini membuat kita yakin bahwa kita, manusia, juga dipengaruhi oleh informasi yang kita terima karena $70 \%$ tubuh manusia dewasa adalah air. Konsekuensi logisnya adalah manusia, sebagai makhluk yang sebagian besarnya terbentuk dari air, sudah seharusnya diberikan informasi yang baik. Jika kita melakukan hal ini, pikiran dan tubuh kita akan menjadi sehat. Di pihak lain, jika kita menerima informasi yang buruk, kita akan merasakan sakit.

\section{DAFTAR PUSTAKA}

Anton Baker, Ontologi, Metafisika Umum : Filsafat Pengada dan Dasar-Dasar Kenyataan (Yogyakarta: Kanisius, 1992)

Callender, C. (2011). Philosophy of Science and Metaphysics. The Continuum Companion to the Philosophy of Science, pp. 33-54. [Online]. Tersedia: http://philosophyfaculty.ecsd.edu

Firman, Harry. (2016) Pengantar Singkat Filsafat. Bahan ajar Filsafat IImu Program Pascasarjana UPI. Tidak diterbitkan

Hamlyn, DW, (1993)“Metaphysics, History Of”, dalam Honderich, dalam makalah Sindung Tjahyadi, Metafisika : Sebuah Kencan Singkat di Akhir Mei 2008,

Hunnex, MD. Chronological and Thematic Charts Of Philosophies and Philosopher (Michigan: academie Books, 1986) 
6 | Titian IImu: Jurnal IImiah Multi Sciences, Vol. IX No. 1, 2017

Jujun S. Suriasumantri. (2011) Tentang Hakikat, dalam Ilmu dalam Persepektif dalam Amsal Bahtiar, Filsafat IIImu, Edisin Revisi Jakarta: PT Raja Grafindo Persada.

Kuhn,TS (1989) "Peran Paradigma dalam Revolusi Sains”. Bandung : Rosda karya

Massaru, Emuto (2005), The Message From water. International water for life Foundation. Jafan

Mumford, S. (2008). Metaphysics. The Routledge Companion to Philosophy of Science, pp. 26-35. [Online].Tersedia:http://sociology.sunimc.net

Sutardjo A. Wiramihardja, Pengantar Filsafat, (Jakarta: PT. Refika Aditama, 2006).

Zainal Abidin, Filsafat Manusia, Edisi Revisi (Bandung, PT Remaja Rosda Karya, 2006) 